\title{
RICARDO KRONE E AS PESQUISAS ARQUEOLÓGICAS NO VALE DO RIBEIRA DE IGUAPE, SP
}

Walter Fagundes Morales*

O objetivo deste artigo é discutir as pesquisas arqueológicas desenvolvidas no começo do século por Ricardo Krone - um dos pioneiros no estudo dos sambaquis brasilęiros - e publicadas em revistas de grande respaldo acadêmico da época, como a Revista do Museu Paulista, a do Instituto Histórico e Geográfico de São Paulo e os Arquivos do Museu Nacional do Rio de Janeiro. À primeira vista, o estudo da bibliografia de Ricardo Krone e a dos seus contemporâneos surpreende, quando comparada com os trabalhos atuais, pela coincidência dos temas e atualidade das questões envolvidas.

Para nortear a discussão, e servir como ponto de referência das idéias de Krone, escolheu-se o seu trabalho mais completo e conhecido sobre sambaquis, aquele entitulado "Informações Ethnographicas do Valle do Rio Ribeira de Iguape", publicado em 1908 (e reeditado em 1914) pela Comissão Geológica e Geográfica de São Paulo. A partir deste texto, que pode ser considerado uma versão bastante melhorada, ampliada e corrigida do seu primeiro artigo "Contribuições para a Ethnologia Paulista" de 1902, Ricardo Krone acreditou haver reunido informações arqueográficas suficientes para traçar a origem dos povos sambaquieiros, escrevendo, em 1911, seu último artigo sobre sambaquis, denominado "O Ídolo Anthropomorpho de Iguape - sua relação com os sambaquis e a prehistoria Brazileira".

A primeira grande polêmica envolvendo os sambaquis, que dividiu a opinião dos estudiosos no começo deste século, relacionava-se à natureza desses sítios, ou seja, se eram naturais ou produto da ação humana (Leonardos 1938; Prous 1992; Mendonça de Souza 1991). Desde seu primeiro artigo (1902: 470), Krone se posicionou claramente a favor da origem artificial dos sambaquis, afirmando

$\left(^{*}\right)$ Museu de Arqueologia e Etnologia. Pós-Graduação em Arqueologia, Mestrado. que "ainda não encontrei um só casqueiro que não me oferecesse todas as garantias de formação artificial pelo homem", sendo mais enfático e contundente no trabalho de 1908 ao afirmar: "sobre a origem artificial das ostreiras só pode estar em duvida quem de visu não as conhece" (p. 24).

É interessante notar, através dos seus artigos, como Krone sempre se manteve dentro do debate sobre a origem dos sambaquis, mas evitando tornálo uma questão pessoal. Pode-se afirmar que, para ele, a origem artificial desses sítios era tão indubitável que discutir exaustivamente tal assunto representaria uma perda de tempo. Mais produtivo que apenas tratar sobre a natureza da origem dos sambaquis, seria aprofundar suas pesquisas em outros aspectos. Outros, como Alberto Löfgren, não pensavam assim. Para Löfgren, um ardente defensor da corrente artificialista, $o$ assunto estava longe de estar encerrado e devia ser debatido à exaustão. Mesmo tendo publicado em 1893 o excelente trabalho "Os Sambaquis de São Paulo", onde demonstra a origem artificial desses sítios, Löfgren dez anos depois (1903) escreve um artigo que resume todas as suas idéias anteriormente publicadas, apenas com o intuito de rebater os argumentos dos naturalistas, mais especificamente de Hermann von Ihering que, não por acaso, também publica neste mesmo volume da Revista do Instituto Histórico e Geográfico de São Paulo, o texto "A Origem dos Sambaquis" (Ihering 1903).

Hermann von Ihering, então diretor do Museu Paulista, era certamente o pesquisador de maior peso e destaque dentro da corrente naturalista e que, por caminhos muitas vezes bastante complicados, defendia firmemente seu ponto de vista, no qual os sambaquis se formaram debaixo d'água e de maneira natural. Ihering (1903 e 1904) até admitia a possibilidade de alguns sambaquis menores serem restos de cozinha dos indígenas, mas nunca os grandes, devido, em linhas gerais, aos seguintes motivos: 1) impossibilidade de ocorrer de forma artificial a sobreposição de camadas de moluscos 
de uma só espécie de cada vez, já que os índios não iriam coletar alternadamente sua fonte de alimento; 2) encontrar na composição das camadas dos sambaquis grande quantidade de conchas pequenas, inúteis para o consumo humano, misturadas a caramujos e ostras maiores, que apesar de servirem como alimento, estavam intactas; 3) a total impossibilidade dos indígenas, indolentes por natureza, em transportar mariscos para formar montes intencionalmente; e 4) ausência de pedaços de carvão vegetal resultantes de fogueiras ou restos de ossos da fauna local. Como justificativa para os ossos humanos encontrados em grande quantidade nos sambaquis, Ihering desenvolve a teoria segundo a qual os sepultamentos resultavam de índios afogados e/ou sepultamentos realizados posteriormente por grupos indígenas mais recentes sobre os montes de conchas. Os únicos sambaquis artificiais, isto é, produto humano, seriam aqueles compostos por terra escura misturada às conchas, com carvão vegetal, ossos de fauna, sepultamentos e artefatos de pedra e restos de panelas de barro em sua composição. Esta discussão perdurou até os anos 40 , quando a teoria artificialista foi finalmente aceita por completo.

Para muitos autores, Krone foi pioneiro ao relacionar variações pretéritas nos níveis marinhos através da implantação dos sambaquis (Prous 1992, Mendonça de Souza 1991). Durante suas pesquisas na região de Iguape, Krone percebeu dois nítidos alinhamentos de sambaquis, um próximo à costa atual e outro mais afastado, rumo ao interior. A partir desse fato, e considerando que a implantação desse tipo de sítio estava intimamente relacionada à disponibilidade dos mariscos e estes aos níveis das marés, concluiu que o Oceano Atlântico, alguns milênios antes, deveria estar naquela região mais interiorana, vários metros acima da cota da linha da costa atual, pois somente desta forma seria possível atingir o alinhamento dos sambaquis mais recuados. Nas palavras do próprio autor (1908:23) " $a$ posição dos sambaquis, reconhecidos como os mais antigos, nos faculta reconstruir uma primitiva linha da costa, bem definida, e nos prova por completo a solidificação de uma zona de mais de 30 kilometros de diametro em frente da primitiva barra do rio Ribeira no Oceano Atlântico".

Entretanto, a possibilidade de correlacionar alterações na estabilidade da linha da costa não corresponde a uma idéia original do próprio Ricardo Krone. Vários anos antes, Carlos Wiener, no primeiro volume dos Arquivos do Museu Nacional do Rio de Janeiro, em 1876, já havia apontado esta possibilidade ao afirmar "primeiro que tudo, a costa brazileira acha-se sujeita, ha grande numero de seculos, a uma sublevação lenta e contínua...” (p. 5) “... e que cada sambaqui, qualquer que seja sua distancia do mar, deve ter sido, na épocha de sua formação, banhado pelo Oceano. Qualquer que seja a origem deste deposito de conchas, quer natural, quer artificial, é logico admittir que um dia cada sambaqui servio de cordão do littoral..." (p. 18). E até mesmo cinco anos antes de Wiener, em 1871, Carlos Rath já havia sugerido que "as marés de nosso tempo não alcançam mais estes depositos conhecidos pelo nome indigena de - sambagué. " (p. 287) ou Ihering (1895:95), que apesar de contestar a origem artificial dos sambaquis declara que "como elles forão feitos no tempo quando o mar estava neste lugar, são elles o signal de modificações na topographia da respectiva região; modificações que não podem ser de hoje nem do seculo passado a antiguidade dos respectivos sambaquis..."

Pode-se perceber com isso que a idéia de associar a implantação de sambaquis às alterações do nível do mar e à demarcação de paleolinhas da costa não era algo inédito, mas que fazia parte de uma perspectiva comum aos pesquisadores daquela época. $\mathrm{O}$ verdadeiro destaque de Krone foi ser o primeiro a efetivamente sistematizar este estudo e marcar as paleolinhas da costa em um mapa e publicá-lo, no caso, o "Esboço da região da foz do Rio Ribeira no começo da Época pleistocena e das suas modificações ate a actualidade" (Krone 1908: 31). É interessante destacar que várias décadas depois, já nos anos setenta, a idéia de relacionar o local de implantação dos sambaquis com os antigos níveis do mar volta à tona (Martin, Suguio, Flexor 1984), e que antigos pioneiros como Wiener, Krone, Ihering ou Rath não são sequer citados.

Um dos principais interesses de Krone desde o início de suas pesquisas foi estudar detalhadamente os sepultamentos e as características físicas dos crânios retirados dos sambaquis, pois, para ele (1902: 472), "o fim principal de uma exploração de sambaquis deve ser o esclarecimento e a descripção de todos os pormenores, que se possam observar na occasião de descobrir esqueletos humanos. Estas descripções, provenientes de diversas zonas, depois de confrontadas, devem por força entre si offerecer pontos de contacto, principalmente 
nos resultados craneometricos comparativos". Neste mesmo trabalho também diagnosticou que os esqueletos humanos dos sambaquis "mais recentes", isto é, junto à atual linha da costa, possuíam grandes variações entre os crânios nas diferentes camadas, levando-o a concluir a existência de "mais de um ramo da grande familia humana" (p. 475). Conclui ainda que os sambaquieiros não teriam o hábito de sepultarem seus mortos, deixando-os insepultos ou mal cobertos na superfície do terreno. Entretanto, com a continuidade de suas pesquisas Krone (1908:29) revê estas interpretações, tendo descoberto "(...) provas da occorrencia de inhumação proposital..." e que "os individuos, cujos esqueletos encontrei nos sambaquis dessa zona, pertenciam a um só typo ethnico, apezar de grandes differenças individuaes".

O equívoco sobre a ausência de inumação nos sepultamentos, descrita no trabalho de 1902, deuse provavelmente em função dos trabalhos de Löfgren e Wiener, ambos especialistas de respaldo em sambaquis e aos quais Ricardo Krone muito respeitava, e que não haviam percebido a intencionalidade nos sepultamentos durante suas próprias escavações. Löfgren (1893:60) “... exclue inteiramente a ideia de um enterramento de corpos inteiros e segundo algum rito ou ceremonia" e " a posição destes ossos humanos é tal que induz a crêr que nenhuma ordem ou disposição ou ceremonia precedia a inhumação; ao contrario acham-se elles na maior confusão possivel..." (p. 25), e da mesma maneira para Wiener (1876:17) "é fora de duvida que nunca estes corpos foram depositados inteiros nos sambaquis". Contudo, é bom ressaltar que nem todos os pesquisadores de sambaquis concordavam com a posição inicial de Krone, ou com a de Wiener e Löfgren, sobre a falta de intencionalidade na inumação dos sepultamentos. Domingos Ferreira Penna (1876), por exemplo, estudando os sambaquis do Pará, já havia encontrado evidências claras da existência de sepultamentos intencionais entre os grupos sambaquieiros, e também Carlos von Koseritz (1884), que relatou saber da retirada de dois esqueletos completos de um grande sambaqui na região da Conceição do Arroio.

Ao perceber a existência de dois alinhamentos de sambaquis, um mais recuado e outro mais próximo da costa atual, como já foi dito, Krone classificou os sambaquis em antigos e modernos respectivamente. A partir dessa primeira e ampla divisão temporal, $o$ interesse passou a ser encontrar varia- ções tipológicas nos artefatos retirados desses sambaquis que propiciassem a datação de cada um desses sítios individualmente. Nesta época os conceitos teóricos evolucionistas aplicados às indústrias líticas preconizavam a existência de um constante aperfeiçoamento dos artefatos ao longo do tempo, ou seja, quanto melhor acabados seriam mais recentes e quanto mais "primitivos" mais antigos. Contudo, vários arqueólogos brasileiros estavam deparando com um quadro mais complexo em suas pesquisas ao encontrar indústrias compostas tanto por material polido quanto lascado, onde a padronização européia da idade da pedra lascada e da pedra polida não podiam ser aplicadas automaticamente.

Pesquisadores como Carlos Wiener, estudando indústrias líticas de sambaquis do Sul do Brasil, e Hermann von Ihering, examinando coleções das mais variadas procedências do Brasil doadas ao Museu Paulista, perceberam o erro da aplicação de conceitos europeus diretamente à arqueologia brasileira, apesar de chegarem, ao término de suas análises, a interpretações bem diversas. Wiener propôs (1876:20) “... que na America a épocha da pedra polida precedeu por muito tempo a da pedra lascada" e Ihering, bem mais familiarizado com o estudos de coleções arqueológicas das mais variadas partes do Brasil, definiu acertadamente que (1895:61), "ao contrario da Europa na América do Sul e em geral em toda a América, os dous typos (de indústrias líticas) coexistem, ao passo que na Europa um seguiu o outro". Ricardo Krone (1908:27), empregando esse mesmo enfoque evolucionista na análise dos artefatos encontrados no Vale do Ribeira, concluiu a existência de uma unidade cultural e étnica entre os sambaquis modernos e os antigos, e que "... em todas as alturas nos sambaquis, nota-se um certo grau de aperfeiçoamento crescente" (dos artefatos), citando as variações estilísticas na elaboração dos machados, que nos sambaquis antigos estão amolados e polidos apenas em sua extremidade e nos modernos em todo o corpo da peça.

Um outro assunto bastante polêmico no começo do século era estimar a idade dos sambaquis, pois os métodos de datação por C-14 ainda não existiam, e as estimativas eram feitas apenas em função de uma série de variáveis muitas vezes subjetivas e pouco confiáveis. Krone (1908:29), nesta discussão, entendia que os grupos sambaquieiros eram bem antigos, remetendo-os ao pleistoceno pois "1) os sambaquieiros não conheciam louça, senão na sua 
forma mais rustica e só pouco antes do seu desapparecimento; 2) não encontrei nos sambaquis primitivos senão restos desfeitos de ossadas humanas; 3) as pedras, que serviam para ferir fogo, são quasi sempre mais ou menos metamorphoseadas ou completamente decompostas em oxydos, na sua parte metallica e 4) desde o inicio dos primeiros sambaquis houve logar uma importante modificação geologica de toda uma vasta região".

Para autores como Carlos von Koseritz a época da formação dos sambaquis também atingia datas recuadas, em torno de até 6.000 anos. $O$ único problema é que os critérios que utilizava para essa estimativa eram bastante duvidosos e pouco detalhados. Koseritz explicita apenas que tomou como base os artefatos encontrados e a existência de espécies de moluscos extintos que remetem a época "anti-diluvial" (Koseritz 1884). Já Löfgren, ao estimar a idade dos concheiros paulistas, calculou o tempo de sua possível elaboração em dois ou três séculos, somando um igual tempo para sua total cobertura vegetal após o abandono, o que dá em torno de 600 a 700 anos antes da chegada dos portugueses. Para Carlos Wiener (1876: 19), “...se póde determinar até um certo ponto a edade relativa do sambaqui, pela distancia que o separa do littoral, sendo, por isso, o mais antigo o que se achar mais afastado da praia".

É interessante perceber como Wiener e Krone, partindo da mesma premissa, isto é, a percepção do recuo da linha da costa através dos sambaquis, chegaram a cálculos temporais tão diferenciados, já que para Wiener muitos dos montes de conchas teriam no máximo três séculos, e para Krone, remeteriam ao pleistoceno. É oportuno acrescentar que Hermann von Ihering, apesar de contestar a origem artificial dos sambaquis, está plenamente convencido da sua formação pleistocênica e das alterações do nível do mar, tal qual Ricardo Krone, pois, segundo Ihering (1903:456) "é justamente nesta épocha pleistocena que se deu a formação submarina dos sambaquis, seguindo-se mais tarde o levantamento da zona costeira para cuja continuação, mesmo ainda no periodo historico temos muitas provas" (p. 456). Como último comentário sobre as enormes variações atribuídas à idade dos sambaquis vale citar, quase a título de curiosidade, a conclusão de J. M. Paldaof (1900: 347) acerca da formação dos sambaquis em período histórico, pois “...no grande sambaqui da Cidreira encontraram-se juntos um pedaço de agatha, os maxillares inferiores do gambá, um crystal de quartzo e, que mais importa uma bala redonda de chumbo (de espingarda)".

Depois de vários anos de estudos arqueológicos que o fizeram conhecido e citado até os dias de hoje, Krone resolve publicar uma síntese interpretativa da origem e proveniência dos povos sambaquieiros na Revista do Instituto Histórico e Geográfico de São Paulo (1911), com o título “O Î́dolo Anthropomorpho de Iguape - sua relação com os sambaquis e a prehistoria Brazileira". Krone tenta demonstrar que ídolos e zoomorfos semelhantes aos brasileiros fazem parte da cultura Calchaqui, do Peru, baseado nas informações de um artigo de Hermann von Ihering (1907: 246) onde este autor afirma que "em Buenos Aires, em varias collecções publicas, vi almofarizes em forma de aves vôando, isto é, ornithomorphos, bem semelhantes aos dos sambaquis. Eis pela primeira vez achados archeologicos, que admittem, ou antes provocam uma comparação da cultura dos sambaquis com outra, que é a dos Calchaquis. A falta completa de objectos ceramicos e metallicos nos sambaquis exclue uma comparação franca e estou longe de affirmar que os habitantes dos sambaquis fossem Calchaquis; insisto, porem, na grande importancia desta concordancia archeologica, que ha de servir de base para investigações ulteriores".

A partir desta informação indireta e pouco conclusiva, somada aos seus estudos anteriores e à análise do famoso ídolo antropomorfo encontrado em Iguape, Krone acredita haver finalmente descoberto a origem dos povos sambaquieiros, traçando os motivos da sua vinda para o litoral brasileiro e as causas de sua descaracterização cultural. Segundo Krone, os Calchaquis, quando da vinda dos espanhóis para a América, estavam sob o domínio Inca havia vários séculos. Por suas características de tolerância, os Incas não devem ter causado a migração dos Calchaquis, mas estes sim teriam causado, muito tempo antes dos Incas, a fuga de um outro povo para a costa do Brasil. Sempre segundo Krone, este povo expulso pelos Calchaquis fez um longa migração, perdendo neste percurso uma série de características da sua cultura original, numa espécie de involução, passando do sedentarismo ao nomadismo e deixando de elaborar objetos cerâmicos ou obras arquitetônicas. Os objetos originais, como os machados, foram se gastando com o uso e a elaboração de novos aos poucos, perdeu seu requinte, transformando-se em instru- 
mentos cada vez mais rústicos, exatamente como são os artefatos retirados dos sambaquis mais antigos. Krone também concluiu que apesar dessa descaracterização cultural, após se fixarem definitivamente no litoral brasileiro, os sambaquieiros readquiriram algumas das habilidades perdidas durante a longa viagem, refletindo em um melhor acabamento dos machados encontrados nos sambaquis mais recentes.

As conclusões a que Ricardo Krone chegou no texto sobre o ídolo de Iguape (1911), já haviam sido sugeridas no trabalho de 1908 , na página 29 , quando ele afirma que o motivo de nunca haver encontrado restos ou ao menos pedaços de peças zoomorfas ou antropomorfas em processo de elaboração "é porque os sambaquieiros não o faziam. Como estes objectos de verdadeira arte vieram então parar nas mão delles? É porque os herdaram dos seus antepassados, que tinham maior habilidade e possuiam uma cultura, que os sambaquieiros, em viagens de duração de séculos perderam". As interpretações de Krone neste artigo, apesar de equivocadas e até preconceituosas quando analisadas à luz dos conhecimentos atuais, são perfeitamente compatíveis e justificáveis dentro de um contexto teórico daquele período, onde as correntes evolucionistas e difusionistas estavam presente de forma marcante. Durante boa parte do século passado e início deste, a humanidade passou a ser comparada e dividida pela conhecida classificação de Morgan entre a civilização, a barbárie e a selvageria, onde cada povo estaria, ou ao menos teria passado, por uma destas etapas em momentos diferentes rumo a uma evolução unidirecional (Morgan 1971). No ponto mais alto da cadeia evolutiva estaria a sociedade européia ocidental, e na base dessa cadeia estariam os indígenas brasileiros (Schwarcz 1993). O texto "O Ídolo Anthropomorpho" somente se enquadra na postura intelectual evolucionista e difusionista do período.

Durante os muitos anos em que Krone pesquisou o Vale do Ribeira, seu interesse não se limitou apenas ao estudo dos sambaquis, alcançando também outros grupos humanos que ocupavam a área em tempos pré-coloniais, como é possível perceber em seu último trabalho, "Notas de prehistoria paulista - O cemitério de Pombéva", publicado em 1918. Neste texto temos uma breve descrição de um grande sepultamento coletivo de 22 indivíduos encontrado em Ilha Comprida, SP, com a análise detalhada dos 4 crânios em melhor esta- do de conservação e a apresentação de vários desenhos e tabelas craniométricas. No próprio trabalho de 1908, Krone já demonstra preocupação em entender o quadro de ocupação do Vale do Ribeira de uma maneira mais abrangente, ao reservar as páginas finais desse artigo para relatar a retirada de diversos sepultamentos, principalmente em urnas, e fazer comentários sobre os aldeamentos guaranis que ainda existiam na região.

Mas Krone não publicou somente trabalhos relacionados à arqueologia. Em 1909 escreve o "Estudo sobre as cavernas do Vale do Rio Ribeira de Iguape" (transcrito na Revista do Instituto Geográfico e Geológico vol. 8 em 1950), onde oferece uma descrição genérica das teorias existentes sobre as origens dessas formações e um extenso índice das cavernas e grutas da região do Ribeira, com o nome e localização aproximada de cada uma delas. A intenção de Ricardo Krone em estudar cavernas é a possibilidade de encontrar em seu interior evidências arqueológicas que possam relacionar os grupos sambaquieiros do Ribeira aos achados de Lund e à "raça de Lagoa Santa" em Minas Gerais. Esse interesse vem de longa data, pois desde seu primeiro texto em 1902, depois de estudar o crânio $17 \mathrm{NB}$ da coleção de Lund, afirma que "sabemos que os conchyliophagos não moravam só na costa, de onde se retiravam temporariamente para serra acima, combinando todos os caracteres morphicos, craneanos e faciaes, não é para duvidar que esse craneo pertencesse a um individuo da Raça dos Sambaquis" (p. 477). Finalmente, emo "Ídolo de Iguape" (1911:232), Krone acredita haver conseguido seu intuito, ao afirmar ter "uma base segura para julgarmos a edade do homem nessa região e ainda sua origem ao homem pleistoceno da Lagoa Santa em Minas Gerais ajunta-se o da mesma epoca da Ribeira em São Paulo" levantando a hipótese de localizar em pesquisas futuras o homem pliocênico nas grutas de calcário de Iporanga, "talvez autochtono destas paragens" (p. 233).

\section{Conclusão}

A leitura dos trabalhos de Ricardo Krone e de vários dos seus contemporâneos, apesar de escritos há mais de cem anos, ultrapassa o interesse de conhecer a história e o passado da arqueologia brasileira e assume grande importância no estudo dos sambaquis atuais. Nestes antigos textos é pos- 
sível encontrar uma grande quantidade de informações sobre sambaquis que não existem mais, e que, no entanto, foram estudados e descritos por pesquisadores como Ricardo Krone antes, ou até mesmo durante, o processo de sua destruição. Resgatar as informações destes artigos, ou até mesmo os originais de campo escritos por esses pioneiros - que estão atualmente espalhados por inúmeras bibliotecas e acervos do Brasil - é um caminho válido para diminuir uma interessante contradição que envolve as pesquisas desenvolvidas em sambaquis: a de serem estes um dos temas mais estudados, porém, menos conhecidos na arqueologia brasileira.

\section{Referências bibliográficas}

IHERING, H.V.

1895 A Civilização Prehistórica do Brazil Meridional. Revista do Museu Paulista, I: 35-159.

1903 A Origem dos Sambaquis. Revista do Instituto Histórico e Geographico de São Paulo. Typ. do Diário Oficial, VIII: 446-457.

1904 Archeologia comparativa do Brazil. Revista do Museu Paulista, VI: 519-580.

1907 A anthropologia do estado de São Paulo. Revista do Museu Paulista, VII: 202-257.

KOSERITZ, C.V

1884 Sambaquis da Conceição do Arroio. Revista do Instituto Historico e Geographico Brasileiro. Rio de Janeiro, 47 (1): 179-182.

KRONE, R.

1902 Contribuições para a ethnologia Paulista. Revista do Instituto Histórico e Geographico de São Paulo. Typ. do Diário Official, VII: 470-480.

1908 Informações ethnográficas do valle do Rio Ribeira de Iguape. Comissão Geographica e Geologica do Estado de São Paulo. São Paulo, Typographia Brazil de Rothschild \& Co.: 23-34.

1909 Estudo sobre as cavernas do Vale do Ribeira. Arquivos do Museu Nacional, Rio de Janeiro, 15: 1909.

1911 O idolo anthropomorpho de Iguape - sua relação com os sambaquis e a prehistoria brazileira. Revista do Instituto Histórico e Geographico de São Paulo. Typ. do Diário Official, XVI: 227-233.

1918 Notas de prehistória paulista: o cemitério do Pombéva. Revista do Museu Paulista, X: 165-190.

LEONARDOS, O.H.

1938 Concheiros Naturais e Sambaquis. Publicações Avulsas, 37, Ministério da Agricultura, Rio de Janeiro.

\section{LÖFGREN, A.}

1893 Os Sambaquis de São Paulo (Contribuições para a archeologia paulista). Boletim da Commissão Geographica e Geologica do Estado de São Paulo, 9. São Paulo, Typ. a Vapor de Vanorden \& Comp.
1903 Os Sambaquis. Revista do Instituto Histórico e Geographico de São Paulo. Typ.do Diário Official, VIII: 458-465.

MARTIN, L.; SUGUIO, K.; FLEXOR, J.-M.

1984 Informações adicionais fornecidas pelos sambaquis na reconstrução de paleolinhas de praia quaternária: exemplos da costa do Brasil. $R e$ vista de Pré-História. São Paulo, Universidade de São Paulo, VI: 128-147.

MENDONÇA DE SOUZA, A.A.C.

1991 História da arqueologia brasileira. Pesquisas, Série Antropologia, São Leopoldo, Instituto Anchietano de Pesquisas, 46.

MORGAN, L.H.

1971 La sociéte archaïque. Paris, Ed. Anthropus. PALDAOF, J.M.

1900 Archeologia Rio-Grandense. Revista do Museu Paulista, IV: 339-347.

PENNA, D.S.F.

1876 Breve notícia sobre os sambaquis do Pará. Archivos do Museu Nacional, Rio de Janeiro, Imprensa Industrial, 1: 87-99.

PROUS, A.

1992 Arqueologia Brasileira. Brasília, DF, Editora da Universidade de Brasília.

RATH, C.

1871 Notícia ethnologica sobre um povo que já habitou a costa do Brasil, bem como o seu interior, antes do diluvio universal. Revista do Instituto Historico e Geographico, 39: 287-292.

\section{SCHWARCZ, L.M.}

1993 O espetáculo das raças: cientistas, instituições e questão racial no Brasil - 1870/1930. São Paulo, Companhia das Letras.

WIENER, C.

1876 Estudos sobre os sambaquis do sul do Brazil. Archivos do Museu Nacional, Rio de Janeiro, Imprensa Industrial, 1: 1-20. 